\title{
Community unit performance: factors associated with childhood diarrhea and appropriate treatment in Nyanza Province, Kenya
}

Yoshito Kawakatsu ${ }^{1,2^{*}}$, Junichi Tanaka ${ }^{1}, K_{\text {Kazuya Ogawa }}{ }^{1}$, Kenneth Ogendo ${ }^{3}$ and Sumihisa Honda ${ }^{1}$

\begin{abstract}
Background: The government of Kenya launched its community health strategy in 2006 to improve certain aspects of its community health program. Under the strategy, community units (CUs) were established as level one of the Kenyan health system. A core member at this level is the community health worker (CHW). The objective of this study was to assess the relationship among the performance of the CUs, the prevalence of childhood diarrhea and appropriate treatment for it by controlling individual and community-level factors.

Methods: The main dataset used in this study was the 2011 Nyanza Province county-based Multiple Indicator Cluster Survey (MICS). In addition, based on the list of community units in Nyanza Province, Kenya, we identified the area's CUs and their performance. MICS data and data on CUs were merged using sub-location names. There were 17 individual and two community-level independent variables in this study. Bivariate analysis and a multilevel logistic regression were performed.

Results: Factors significantly associated with a lower prevalence of diarrhea among children under five were the child's increasing age, middle-aged household heads, children who received more attention, water treatment and rural versus urban area residence, while male children and highly performing CUs were significantly associated with a higher prevalence of diarrhea. In addition, middle wealth index, severity of diarrhea and middle- and high-CU performance were significantly associated with appropriate treatment for childhood diarrhea.

Conclusions: Although this study found that children living in areas of high CU performance were more likely to have diarrhea, these areas would have been identified as being more at risk for diarrhea prevalence and other health concerns, prioritized for the establishment of a CU and allocated more resources to improve the performance of CUs. A higher CU performance was significantly associated with the appropriate treatment. It was suggested that CHWs could have a positive effect on the community, as demonstrated and promoted by appropriate health-seeking behavior and treatment for childhood diarrhea.
\end{abstract}

Keywords: Community health worker, Infectious disease, Diarrhea, Health-seeking behavior, Multi-level analysis, Kenya

\footnotetext{
* Correspondence: y.kawakatsu.0829@gmail.com

${ }^{1}$ Graduate School of Biomedical Sciences, Nagasaki University, 1-7-1

Sakamoto, Nagasaki, Japan

${ }^{2}$ Strengthening Pro-Poor Community Health Project, Lagos, Nigeria

Full list of author information is available at the end of the article
} 


\section{Background}

In efforts to achieve universal health coverage (UHC), a key challenge is an inadequate health workforce, especially in resource-poor countries [1]. To deliver essential health interventions to every community, community health workers can undertake a wide range of tasks [2]. It is recommended that investment in building $\mathrm{CHW}$ skills and the maintenance of their performance are beneficial to UHC [3].

To empower households and communities to improve their own health, the Kenyan Government developed and launched the Community Health Strategy (CHS) in 2006. The strategy was well articulated as one of the flagship programs in the National Health Sector Strategic Plan 2005-2010 (NHPP II) [4]. One of the main purposes of this strategy was to enhance access to health care services in order to improve productivity and thus reduce poverty, hunger, and child and maternal deaths. In this strategy, the community unit (CU) is defined as level one of the Kenyan Health System. It consists of a community health committee $(\mathrm{CHC})$, two community health extension workers (CHEWs) and community health workers (CHWs).

The $\mathrm{CHC}$ is the governing body that coordinates all community health activity; its members are community leaders. There are two types of CHEWs in a CU. One is the facility CHEW, who works in a health facility. The other is the community CHEW, who works mostly at the community level. Both supervise the work of the $\mathrm{CHWs}$. Among the groups, CHWs were the only direct service providers to community members.

In each CU, 50 community health workers (CHWs) were selected from the community between 2006 and 2010. The household coverage per CHW was 20. Later in 2010, the implementation strategy of CHS, especially distribution of personnel, was revised and about 10 CHWs were chosen after that. After the revision, the household coverage per CHW was 100 in Nyanza province. As a reward for increased household coverage per person, the government had planned to provide a small stipend. Although all CUs established both before and after the revision should have been standardized, based on the guidance of the Kenyan Ministry of Health $(\mathrm{MoH})$, the progress of the implementation was varied, depending on the funds received from the government, international organizations, and NGOs. As a result, most CHWs were still volunteers in 2011, with the exception of the areas where particular partners paid the allowance. Although the training procedure for CHWs was standardized by the Kenyan $\mathrm{MoH}$, their performance varied and was influenced by individual and contextual factors $[5,6]$.

Within this environment of increased attention to community health issues, the high burden of diarrhea amongst young children was an area of focus as diarrheal diseases were the second leading cause of mortality worldwide among children under five in 2008 [7]. Almost half of these deaths occurred in Africa [7]. Although numerous facility- and community-based interventions have been implemented to improve access to and uptake of effective preventions and treatments [8], the burden of diarrhea is still substantial in sub-Saharan countries. Therefore, prevention of diarrheal diseases was one of the focal areas of CHS in Kenya. The CHWs received the training, including methods for the prevention of diarrhea, water safety, sanitation and hygiene-related issues. According to the recent Kenyan Demographic Health Survey [9], 16.6\% of children under five had experienced diarrheal diseases within the two weeks preceding the survey, and $2.6 \%$ had had severe diarrhea with blood. Among them, 13\% had not received any treatment.

Although CHS was implemented from 2006, few studies have evaluated the impact of CUs and CHWs according to CHS $[5,6,10]$. Therefore, the objective of this study was to assess the performance of CUs and other individual- and community-level factors on the prevalence of diarrhea and its appropriate treatment among children under five in western Kenya.

\section{Methods}

\section{Dataset}

The main dataset used is this study was the Nyanza Province County-based Multiple Indicator Cluster Survey (MICS) of 2011. The detailed survey methodology is available in the Kenya, Nyanza Province Multiple Indicator Cluster Survey 2011 final report [11]. The dataset includes 30,439 household members from 6,828 households that participated in the survey. A structured questionnaire was administered to gather a wide range of information, such as socio-economic characteristics and health conditions. In addition, a list of CUs in Nyanza province, obtained from the Kenyan Ministry of Health, was utilized to identify the communities with CUs and their performance. The total number of CUs in Nyanza province of Kenya was 586. Both MICS data and data on CUs were merged using sub-location names.

\section{Measures \\ Outcome variables}

There were two outcomes of this study. One was the number of cases of diarrhea among children under five years old within the two weeks preceding the survey. In the MICS survey, "Diarrhea is determined as perceived by mother or caretaker, or as three or more loose or watery stools per day, or blood in stool" [11]. Regardless of the severity of each case, we coded a value of 1 if children had had diarrheal symptoms during the two weeks preceding the survey, and a value of 0 if they had had no 
symptoms. The second outcome was the parent or caregiver's treatment choice for the child's diarrhea. Appropriate treatment for childhood diarrhea in this study, coded as 1, was defined as any of the following treatments: ORS, Zinc, intravenous fluids, or antibiotics for bloody diarrhea, while inappropriate behavior, coded as 0 , was defined as no treatment, herbal medicine or ot her home remedy, antimotility, unknown pill, syrup and injection, or other.

\section{Independent variables}

There were 17 individual and two community-level variables, shown in Table 1. Variables regarding the characteristics of household heads were included in the analysis since these were the people who made decisions or could influence the mother's or caregiver's decision making. Household wealth was calculated by a principal component analysis using the respondents' household assets for the whole survey dataset. This index was used to capture socioeconomic status and was divided into five categories: poorest, poor, middle, rich and richest.

Two binary variables were created: paying attention to the child and playing with the child. These variables indicated the degree of parental and family attention and care given to children. The variable 'paying attention to the child' was generated by the question: "Sometimes adults taking care of children have to leave the house to go shopping, wash clothes, or for other reasons and have to leave young children. On how many days in the past weeks was (name) left alone? or left in the care of another child (that is, someone less than 10 years old)?" [11]. The variable was classified into two groups: children who were paid less attention by family members and children who were paid more attention. That is, if the participants answered "one or more days left their children alone or only with other young children," they were categorized as children who were paid less attention. If children always remained with adults, they were categorized as children who were paid more attention. As a result of being left alone or only with other young children, children are more at risk of suffering accidents [11]. 'Playing with a child' was created by using four questions as to whether or not household members had engaged in the following activities in the previous three days: reading books, taking the child outside, playing with the child, and naming, counting or drawing with the child. 'Playing with a child' was categorized as either playing with the child at least once in the past three days or not playing with the child at all during this time period.

Identifying the source for drinking water was generated from a question about the main source of drinking water for household members. Improved drinking water sources included piped water, protected wells, protected springs, tubewell or borehole, rainwater and bottled water [12]. This variable was coded as 'improved' or 'unimproved'.

Water treatment was the methods to make water clean and safe to drink, which was categorized as "no treatment or inadequate" and "adequate treatment". Adequate water treatment was defined as methods to disinfect water by killing harmful pathogens, such as boiling, adding bleach or chlorine, and using a water filter [12]. If one of these methods was used in the household, it was categorized as adequate treatment. Inadequate methods which were not sufficient to disinfect water included the choices; "strain it through a cloth" and "let it stand and settle" [12].

There were two additional variables for the analysis of appropriate treatment: possession of media devices and severity of diarrhea. Possession of media devices included radio, TV, mobile or landline phone, computer and the Internet. If a family had at least one of these devices, we grouped it as a household with at least a media device. Another variable, severe diarrhea, was defined as diarrhea with blood.

There were two community level variables: Area (rural or urban) and the performance of the CUs. The definition of rural and urban was provided in the 2009 Kenya Population and Housing Census [13]. The performance of the CUs was determined using three criteria developed by the Kenyan Ministry of Public Health and Sanitation (MoPHS). The first was the presence of minutes of monthly meetings, such as Dialogue Days and Action Days; the second was the presence of all key persons (CHC, CHWs, and CHEWs), all of whom must have finished the standardized training program, and the third was the presence of reporting tools for the community health information system (CHIS). Dialogue Day and Action Day meetings are held monthly with the CHC, CHWs, CHEWs and people from the community. In the Dialogue Day meeting, current health problems within the community and how to solve them are discussed. Action Day is a day to implement the solution decided on during the Dialogue Day meeting. There are two main official reporting tools in the CHIS: the CHW service delivery log book and the CHEW summary. After summarizing the CHW service delivery log book using the CHEW summary tool, the latter is submitted to the CHS focal person in a district followed by the CHS departments at provincial and national levels.

Each of these variables scored 1 if it they were available. If CUs received three points, they were considered "high performance CUs" because they had all required materials and functions based on the criteria. CUs with scores of 1 or 2 were categorized as "middle performance CUs." CUs with a score of "0," as well as areas without CUs, were regarded as reference groups, 
Table 1 Sample characteristics of children under five and their families MICS survey 2011 Nyanza, Kenya

Dependent variables $N(\%)$

Experienced diarrhea within the previous 2 weeks

$$
\begin{array}{ll}
\text { Yes } & 781(15.8) \\
\text { No } & 4174(84.2)
\end{array}
$$

Appropriate treatment for childhood diarrhea

$$
\text { Inappropriate }
$$

Appropriate

$291(37.3)$

Unknown

$9(1.2)$

\section{Individual Variables for both analyses}

Child's gender

$$
\text { Female }
$$$$
\text { Male }
$$

Child's age (years)

$$
<1
$$$$
1
$$$$
2
$$$$
3
$$$$
4
$$

Relationship to household head

$$
\begin{aligned}
& \text { Biological child } \\
& \text { Grandchild } \\
& \text { Other }
\end{aligned}
$$

$$
\begin{aligned}
& 969(19.6) \\
& 863(17.4) \\
& 1017(20.5) \\
& 1093(22.1) \\
& 1013(20.4)
\end{aligned}
$$

Household head's gender

$$
\text { Female }
$$

Male

$3912(79.0)$

$872(17.6)$

$171(3.5)$

1236 (24.9)

$3719(75.1)$

Age group (years)

$$
\begin{aligned}
& <30 \\
& 30-34 \\
& 35-39 \\
& 40-49 \\
& \geq 50
\end{aligned}
$$

$934(18.9)$

$814(16.4)$

$858(17.3)$

$979(19.8)$

Education level

No education/Primary level

$3390(68.4)$

Secondary level or higher

Household wealth index

Poorer
Poor
Middle
Rich
Richer

Number of household members

5 or fewer than 5

$2406(48.6)$

More than 5

$2549(51.4)$
Table 1 Sample characteristics of children under five and their families MICS survey 2011 Nyanza, Kenya (Continued)

Number of children under five

$$
\text { One }
$$

More than 1

3402 (68.7)

Paying attention to the child

$\begin{array}{ll}\text { Less attention } & 2780(56.1) \\ \text { More attention } & 2175(43.9)\end{array}$

Playing with the child

$$
\begin{array}{ll}
\text { No playing } & 1012(20.4) \\
\text { Playing at least once within the past } 3 \text { days } & 3943(79.6)
\end{array}
$$

\section{Individual Variables for the first analysis on diarrhea cases}

Water source for drinking

$\begin{array}{ll}\text { Unimproved sources of drinking water } & 2445(54.3) \\ \text { Unprotected well } & 410(8.3) \\ \text { Unprotected spring } & 606(12.2) \\ \text { Tanker-truck } & 3(0.1) \\ \text { Cart with small tank/drum } & 14(0.3) \\ \text { Surface water } & 1412(28.5) \\ \text { Improved sources of drinking water } & 2510(45.7) \\ \text { Piped water } & 471(9.5) \\ \text { Protected well } & 311(6.7) \\ \text { Protected spring } & 971(19.6) \\ \text { Public tap/standpipe } & 246(5.0) \\ \text { Tubewell/borehole } & 247(5.0) \\ \text { Rainwater collection } & 244(4.9) \\ \text { Bottle water } & 0(0.0)\end{array}$

Water treatment

$$
\begin{array}{ll}
\text { No treatment } & 2104(42.5) \\
\text { Inadequate treatment only } & 113(2.3) \\
\text { Adequate treatment } & 2738(55.3)
\end{array}
$$

Hand-washing facility

Not available $\quad 4809(97.1)$

Possession of refrigerator
No
$4868(98.2)$
Yes
$87(1.8)$

Individual Variables for the second analysis on appropriate treatment

Severity of diarrhea

$\begin{array}{ll}\text { Without blood } & 673(87.2) \\ \text { With blood } & 99(12.8)\end{array}$

Possession of at least one media device

No

$80(10.4)$
Yes
692 (89.6) 
Table 1 Sample characteristics of children under five and their families MICS survey 2011 Nyanza, Kenya (Continued)

\begin{tabular}{ll}
\hline Community Variables for the two analyses & $\mathrm{N}(\%)$ \\
Area & \\
Urban & $505(10.2)$ \\
Rural & $4450(89.8)$ \\
Performance of CHWs in the CU & $\mathrm{N} / \mathrm{CUs}(\%)$ \\
$\quad$ None/Poor (Number of CHWs and CUs) & $2639 / 156(53.3)$ \\
Middle & $1483 / 91(29.9)$ \\
High & $833 / 51(16.8)$ \\
\hline
\end{tabular}

because the low performing CUs had no evidence of CU activity.

\section{Statistical analysis}

A multilevel logistic regression analysis was performed in order to take account of the hierarchical structure of the data. This meant that individuals (level 1) were nested within communities (level 2). Multilevel analysis is a suitable approach to take into account the community level context, as well as individual characteristics. We computed three models in order to decide upon the most suitable final model. There was no independent variable in model 0 , while only individual variables existed in model 1 and both individual and community variables were present in model 2 . Based on the likelihood ratio test and the variance of random effects, we selected the final model with lower log likelihood and the variance of random effects. Both bivariate and multilevel logistic regression analysis with sample weights were performed using Stata 12 (Stata Corporation, College Station, TX).

\section{Results}

Out of 300 Enumeration Areas (EAs) in the MICS survey, two were excluded because there was no information as to whether or not the CUs had been established. Therefore, the total number of EAs with full sets of CU data used in the analysis was 298. In this matched dataset, there were 5,045 children under five, but there were missing data for dependent and/or independent variables for 90 children. Thus the final sample included in this study was restricted to 4,955 children under five and their family members; this number was used to determine factors relating to childhood diarrhea. The data in Table 1 show that $19.6 \%$ of these children were under one year of age, and $79 \%$ were the biological children of the household heads. The percentages of participants who could access an improved drinking source and adequately treated their drinking water were $45.7 \%$ and $54.3 \%$ respectively. More than half $(53.3 \%)$ lived in areas without $\mathrm{CU}$ or with the low-performing $\mathrm{CU}$.
Out of 4,955 children, 781 (15.8\%) had experienced diarrhea in the two weeks before the survey. However, treatment methods among nine of the children were unknown, so the total number of child participants with diarrhea included in the analysis for the appropriate treatment was 772 (98.8\% of the original 781$)$. In this sample, $12.8 \%$ of their diarrhea was bloody diarrhea, and $37.3 \%$ of them took appropriate treatment.

\section{Factors influencing the prevalence of childhood diarrhea}

Table 2 shows the prevalence of diarrhea and appropriate treatment by independent variables and unadjusted odds ratios. The significant factors in multilevel analysis mentioned below were also significant in bivariate analysis.

Table 3 presents the factors associated with the prevalence of childhood diarrhea in Nyanza Province, Kenya. According to the likelihood ratio test, we concluded that model 2 was the final model. In model 2, the increasing age of the child was negatively associated with the prevalence of childhood diarrhea (AOR: 0.714; 95\%CI: $0.669-$ $0.761 ; p<0.001$ ), while male children were significantly more likely to have diarrheal diseases (AOR: 1.429; 95\%CI: $1.192-1.714 ; p<0.001)$. Compared with households where the head was under 30 years old, children staying with household heads aged 35-39 years old were significantly less likely to have childhood diarrhea (AOR: 0.718; 95\%CI: 0.534-0.967; $p=0.029$ ). A child being paid more attention was less likely to develop diarrheal disease (AOR: 0.693; 95\%CI: 0.579-0.828; $p<0.001$ ). In addition, treating water (AOR: 0.799; 95\%CI: 0.651-0.980; $p=$ 0.031 ) was significantly associated with the prevention of diarrhea. Children living in rural areas were significantly less likely to experience diarrhea symptoms than those living in urban areas (AOR: 0.666; 95\%CI: 0.455-0.996; $p=$ 0.048). Areas with high $\mathrm{CU}$ performance were positively associated with the prevalence of diarrhea, compared with areas without CUs or with poor performing CUs (AOR: 1.347; 95\%CI: $1.003-1.810 ; p=0.048$ ).

\section{Determinants of appropriate treatment for childhood diarrhea}

The results of a bivariate analysis are shown in Table 2 . According to this analysis, the factors significantly associated with appropriate treatment were household wealth index, severity of diarrhea and the performance of the CUs. These were the same significant factors in the multilevel analysis below.

Table 4 shows the determinants of appropriate treatment for childhood diarrhea. Among individual variables in model 2, household wealth and severity of diarrhea were significantly associated with an appropriate treatment. Compared with people in the lowest wealth quintile, children of families in the middle wealth quintile had around twice the odds of receiving 
Table 2 Prevalence of diarrhea and appropriate treatment by independent variables and unadjusted odds ratios in Nyanza, Kenya

\begin{tabular}{l} 
Individual variables for both analyse \\
\hline Child's gender \\
Female \\
Male \\
Child's age (years) \\
$<1$ \\
1 \\
2 \\
3 \\
4 \\
Relationship to household head \\
Biological child \\
Grandchild \\
Other \\
Household head's gender \\
Female \\
Male \\
Age group (years) \\
$<30$ \\
$30-34$ \\
$40-39$ \\
$\geq 50$ \\
\end{tabular}

Education level

No education/Primary level

Secondary level or higher

Household wealth index

Poorer
Poor
Middle
Rich
Richer

Number of household members

5 or fewer than 5

More than 5

Number of children under five

One

More than 1

Paying attention to the child

$$
\begin{aligned}
& \text { Less attention } \\
& \text { More attention }
\end{aligned}
$$

\begin{tabular}{lll}
$\begin{array}{l}\text { Experienced diarrhea within } \\
\text { the previous } 2\end{array}$ & \\
\hline No weeks & Yes & Unadjusted \\
$n(\%)$ & $n(\%)$ & odds ratio
\end{tabular}
Appropriate treatment

n (\%)

$2102(86.1)$

$339(13.9)$

Ref.

2072 (82.4)

$442(17.6) \quad 1.390^{* * *}$

$767(79.2)$

202 (20.9)

Ref.

647 (75.0)

216 (25.0)

$1.259^{*}$

849 (83.5)

168 (16.5)

$0.722^{* *}$

$984(90.0)$

$109(10.0)$

$0.375^{* * *}$

927 (91.5)

$86(8.5)$

$0.350^{* * *}$

3294 (84.2)

618 (15.8)

745 (85.4)

127 (14.6)

Ref.

0.840

$135(79.0)$

$36(21.1)$

1.376

$1,039(84.1)$

197 (15.9)

Ref.

$3,135(84.3)$

584 (15.7)

1.030

$1101(80.4)$

269 (19.6)

$788(84.4)$

146 (15.6)

Ref.

$0.767^{* * *}$

700 (86.0)

114 (14.0)

$0.642^{* * *}$

$750(87.4)$

108 (12.6)

$0.612^{* * *}$

835 (85.3)

$144(14.7)$

$0.681^{* * *}$

2829 (83.5)

$561(16.6)$

Ref.

$220(14.1)$

0.862

985 (84.0)

188 (16.0) Ref.

868 (83.7)

$169(16.3)$

1.054

855 (85.0)

$151(15.0)$

0.960

802 (85.6)

$135(14.4)$

0.906

$664(82.8)$

$138(17.2)$

1.062

2002 (83.2)

404 (16.8)

Ref.

377 (14.8)

$0.824^{*}$

$1340(86.3)$

$213(13.7)$

$2834(83.3)$

$568(16.7)$

Ref.

$1.203^{*}$

2316 (83.3)

464 (16.7)

Ref.

317 (14.6)

$0.844^{*}$

Inappropriate

n (\%)

$213(64.0)$

268 (61.1)

$120(36.0)$

171 (39.0)

Ref.

126 (62.4)

76 (37.6)

Ref.

124 (58.2)

89 (41.8)

1.132

109 (66.1)

56 (33.9)

0.768

64 (59.3)

44 (40.7)

1.131

$58(69.1)$

26 (31.0)

0.601

386 (63.1)

226 (36.9)

Ref.

74 (59.7)

50 (40.3)

1.158

$21(58.3)$

15 (41.7)

1.123

118 (61.8)

73 (38.2)

Ref.

$363(62.5)$

218 (37.5)

1.019

1858 (85.4)
$172(64.9)$

87 (59.6)

93 (35.1)

Ref.

67 (59.8)

59 (40.4)

1.276

66 (62.9)

45 (40.2)

1.433

39 (37.1)

1.034

89 (61.8)

55 (38.2)

1.147

342 (62.0)

$210(38.0)$

Ref.

139 (63.2)

81 (36.8)

0.913

123 (67.2)

60 (32.8)

Ref.

105 (62.5)

63 (37.5)

1.174

85 (56.3)

66 (43.7)

$1.644^{*}$

80 (60.6)

52 (39.4)

1.377

88 (63.8)

$50(36.2)$

1.075

253 (63.3)

147 (36.8)

Ref.

$228(61.3)$

144 (38.7)

1.111

135 (64.6)

74 (35.4)

Ref.

$346(61.5)$

217 (38.5)

1.190

278 (60.4)

182 (39.6)

Ref.

203 (65.1)

109 (34.9)

0.892 
Table 2 Prevalence of diarrhea and appropriate treatment by independent variables and unadjusted odds ratios in Nyanza, Kenya (Continued)

\begin{tabular}{llll}
\hline $\begin{array}{l}\text { Playing with the child in the past three days } \\
\text { No playing }\end{array}$ & $858(84.8)$ & $154(15.2)$ & Ref. \\
Playing at least once within the past 3 days & $3316(84.1)$ & $627(15.9)$ & 1.028 \\
& & & \\
Individual Variables for the first analysis on diarrhea cases & & & \\
Water source for drinking & $2057(84.1)$ & $388(15.9)$ & Ref. \\
$\quad$ Unimproved & $2117(84.3)$ & $393(15.7)$ & 0.974 \\
$\quad$ Improved & $1839(83.0)$ & $378(17.1)$ & Ref. \\
Water treatment & $2335(85.3)$ & $403(14.7)$ & $0.820^{*}$ \\
$\quad$ No treatment/Inadequate & & & \\
Adequate treatment & $4045(84.1)$ & $764(15.9)$ & Ref. \\
Hand-washing facility & $129(88.4)$ & $17(11.6)$ & 0.620 \\
$\quad$ Not available & & & \\
Available & $4096(84.1)$ & $772(15.9)$ & Ref. \\
Possession of refrigerator & $78(89.7)$ & $9(10.3)$ & 0.491
\end{tabular}

Individual Variables for the second analysis on appropriate treatment

Severity of diarrhea

Without blood

With blood

Possession of at least one media device

No

Yes

$\begin{array}{lll}437(64.9) & 236(35.1) & \text { Ref. } \\ 44(44.4) & 55(55.6) & 2.538^{* * *} \\ 47(58.8) & 33(41.3) & \text { Ref. } \\ 434(62.7) & 258(37.3) & 0.809\end{array}$

Community Variables for the two analyses

Area

\begin{tabular}{lllllll} 
Urban & $402(79.6)$ & $103(20.4)$ & Ref. & $66(65.4)$ & $35(34.7)$ & Ref. \\
Rural & $3772(84.8)$ & $678(15.2)$ & $0.753^{*}$ & $415(61.9)$ & $256(38.2)$ & 1.195 \\
formance of CHWs in the CU & & & & & & \\
None/Poor (Number of CHWs and CUs) & $2263(85.8)$ & $376(14.3)$ & Ref. & $248(67.0)$ & $122(33.0)$ & Ref. \\
Middle & $1244(83.9)$ & $239(16.1)$ & 1.194 & $141(59.5)$ & $96(40.5)$ & $1.651^{* *}$ \\
High & $667(80.1)$ & $166(19.9)$ & $1.453^{* *}$ & $92(55.8)$ & $73(44.2)$ & $1.841^{* *}$ \\
\hline
\end{tabular}

${ }^{*} \leq 0.05{ }^{* *} \leq 0.01{ }^{* * *} \leq 0.001$

the necessary health care (AOR: 1.923; 95\%CI: $1.018-$ 3.631; $p=0.044)$. Childhood diarrhea with blood was also significantly associated with an appropriate treatment (AOR: 2.813; 95\%CI: 1.508-5.251; $p=0.001$ ). Compared with areas without CUs or with lower performing CUs, the areas with middle (AOR: 1.655; 95\%CI: $1.080-2.538 ; p=0.021)$ and higher performing (AOR: 1.938; 95\%CI: 1.201-3.127; $p=0.007$ ) CUs had significantly increased odds of practicing appropriate treatment.

\section{Discussion}

This study aims to evaluate the association between the performance of CUs and the prevalence of diarrhea among children under five in Nyanza Province, Kenya, and the appropriate treatment for childhood diarrhea. Compared with the Kenya Demographic Health Survey (KDHS) [9], the percentage of diarrhea cases among children under five was similar: $16.6 \%$ in KDHS and $15.8 \%$ in this study. Since the burden of diarrheal diseases is still substantial, it is clear that more action is 
Table 3 Multilevel logistic regressions predicting factors associated with prevalence of diarrhea among children younger than five years of age in Nyanza Province, Kenya

\begin{tabular}{|c|c|c|c|c|}
\hline \multirow[t]{2}{*}{ Individual variables } & \multicolumn{2}{|l|}{ Model 1} & \multicolumn{2}{|l|}{ Model 2} \\
\hline & Odds ratio & $95 \% \mathrm{Cl}$ & Odds ratio & $95 \% \mathrm{Cl}$ \\
\hline \multicolumn{5}{|l|}{ Child's gender } \\
\hline Female & Ref. & & Ref. & \\
\hline Male & $1.424^{* * *}$ & $1.189-1.706$ & $1.429^{* * *}$ & $1.192-1.714$ \\
\hline Child's age (continuous from 0 to 4) & $0.712^{* * *}$ & $0.668-0.759$ & $0.714^{* * *}$ & $0.669-0.761$ \\
\hline \multicolumn{5}{|l|}{ Relationship to household head } \\
\hline Biological child & Ref. & & Ref. & \\
\hline Grandchild & 0.979 & $0.672-1.427$ & 0.992 & $0.681-1.446$ \\
\hline Other & 1.508 & $0.976-2.328$ & 1.505 & $0.978-2.317$ \\
\hline \multicolumn{5}{|l|}{ Household head's gender } \\
\hline Female & Ref. & & Ref. & \\
\hline Male & 1.003 & $0.810-1.241$ & 1.001 & $0.808-1.240$ \\
\hline \multicolumn{5}{|l|}{ Age group (years) } \\
\hline$<30$ & Ref. & & Ref. & \\
\hline $30-34$ & 0.826 & $0.624-1.094$ & 0.833 & $0.630-1.100$ \\
\hline $35-39$ & $0.719^{*}$ & $0.534-0.968$ & $0.718^{*}$ & $0.534-0.967$ \\
\hline $40-49$ & 0.729 & $0.517-1.029$ & 0.738 & $0.523-1.041$ \\
\hline$\geq 50$ & 0.803 & $0.542-1.189$ & 0.814 & $0.550-1.204$ \\
\hline \multicolumn{5}{|l|}{ Education level } \\
\hline No education/Primary level & Ref. & & Ref. & \\
\hline Secondary level or higher & 0.895 & $0.727-1.101$ & 0.911 & $0.740-1.121$ \\
\hline \multicolumn{5}{|l|}{ Household wealth index } \\
\hline Poorer & Ref. & & Ref. & \\
\hline Poor & 1.148 & $0.874-1.509$ & 1.134 & $0.862-1.491$ \\
\hline Middle & 0.964 & $0.723-1.285$ & 0.946 & $0.709-1.264$ \\
\hline Rich & 0.906 & $0.676-1.214$ & 0.858 & $0.637-1.155$ \\
\hline Richer & 1.237 & $0.885-1.730$ & 1.045 & $0.723-1.510$ \\
\hline \multicolumn{5}{|l|}{ Number of household members } \\
\hline 5 or fewer than 5 & Ref. & & Ref. & \\
\hline More than 5 & 0.933 & $0.748-1.165$ & 0.949 & $0.759-1.186$ \\
\hline \multicolumn{5}{|l|}{ Number of children under five } \\
\hline One & Ref. & & & \\
\hline More than 1 & 1.159 & $0.951-1.413$ & 1.154 & $0.946-1.407$ \\
\hline \multicolumn{5}{|l|}{ Paying attention to the child } \\
\hline Less attention & Ref. & & & \\
\hline More attention & $0.690^{* * *}$ & $0.577-0.824$ & $0.693^{* * *}$ & $0.579-0.828$ \\
\hline \multicolumn{5}{|l|}{ Playing with the child in the past three days } \\
\hline No playing & Ref. & & Ref. & \\
\hline Playing at least once within the past 3 days & 1.084 & $0.844-1.391$ & 1.076 & $0.838-1.381$ \\
\hline \multicolumn{5}{|l|}{ Water source for drinking } \\
\hline Unimproved & Ref. & & Ref. & \\
\hline Improved & 0.956 & $0.775-1.179$ & 0.941 & $0.761-1.164$ \\
\hline
\end{tabular}


Table 3 Multilevel logistic regressions predicting factors associated with prevalence of diarrhea among children younger than five years of age in Nyanza Province, Kenya (Continued)

\begin{tabular}{|c|c|c|c|c|}
\hline \multicolumn{5}{|l|}{ Water treatment } \\
\hline No treatment/Inadequate & Ref. & & Ref. & \\
\hline Adequate treatment & 0.819 & $0.669-1.004$ & $0.799^{*}$ & $0.651-0.980$ \\
\hline \multicolumn{5}{|l|}{ Hand-washing facility } \\
\hline Not available & Ref. & & Ref. & \\
\hline Available & 0.753 & $0.378-1.500$ & 0.741 & $0.368-1.492$ \\
\hline \multicolumn{5}{|l|}{ Possession of refrigerator } \\
\hline No & Ref. & & Ref. & \\
\hline Yes & 0.649 & $0.290-1.451$ & 0.611 & $0.266-1.403$ \\
\hline \multicolumn{5}{|l|}{ Community Variables } \\
\hline \multicolumn{5}{|l|}{ Area } \\
\hline Urban & & & Ref. & \\
\hline Rural & & & $0.666^{*}$ & $0.445-0.996$ \\
\hline \multicolumn{5}{|l|}{ Performance of $\mathrm{CHWs}$ in the $\mathrm{CU}$} \\
\hline None/Poor & & & Ref. & $0.941-1.487$ \\
\hline Middle & & & 1.183 & $1.003-1.810$ \\
\hline High & & & $1.347^{*}$ & \\
\hline Community Level Variance and covariance of random effects & $0.294(0.065)$ & & $0.262(0.061)$ & \\
\hline Log likelihood & -2038.89 & & -2033.98 & \\
\hline Likelihood-ratio test ( $p$ value) & $\leq 0.001$ & & 0.019 & \\
\hline
\end{tabular}

$* \leq 0.05 * * * 0.001$

needed to reduce the incidence of diarrhea. In addition, people in the community must be encouraged to take appropriate action regarding their children's diarrhea. The following significant factors associated with diarrhea prevalence and the appropriate treatments for childhood diarrhea could be useful in developing an effective strategy for both prevention and treatment.

\section{Factors associated with childhood diarrhea}

In our study, the significant factors negatively associated with childhood diarrhoea were the child's increasing age, the household head being in the middle age group, the child being paid more attention, treated drinking water and residence in a rural area, while male children and those in areas with high performing CUs were significantly more likely to have childhood diarrhea.

The areas with high performing CUs were associated with more diarrheal diseases. This might be because $\mathrm{CU}$ establishments were focused more on areas with a high prevalence of diarrhea and other diseases. According to the community health services focal officers at the research sites, the officers are responsible for prioritizing areas that require urgent addressing of health needs, especially childhood diseases, and behavior that leads to poor health by community members, because the Ministry of Health was unable to establish all CUs at the same time. Prioritized areas were therefore chosen for the establishment of CUs and allocation of more resources. Other studies have shown that routine visitation by CHWs was effective in reducing the incidence of childhood diarrhea [14-16]. The study in Kenya also shows that $\mathrm{CU}$ establishment can increase water treatment and latrine use [10], major risk factors of childhood diarrhea. According to the additional bivariate analysis, our data also suggested the same relationship: the areas covered by high performance CUs had a higher percentage of water treatment $(p<0.001)$. It also suggested that CHWs could have a positive impact on the use of water treatment, which may reduce the incidence of childhood diarrhea in the near future.

In this study, children living in rural area were less likely to have experienced diarrhea than children in urban areas. One possible reason for this is that research conducted in Kenya shows that memories among people in rural areas fade more easily than those of urban residents. This means that people in urban areas seem to remember such events well [17]. People living in urban areas might be more cognizant of their children's symptoms because of more information available in urban areas; this would therefore improve their health awareness. In addition, population density is an important determinant influencing risk of disease transmission [18, 19]. This would 
Table 4 Multilevel logistic regressions predicting factors associated with appropriate treatment for childhood diarrhea in Nyanza Province, Kenya

\begin{tabular}{|c|c|c|c|c|}
\hline \multirow[t]{2}{*}{ Individual variables } & \multicolumn{2}{|l|}{ Model 1} & \multicolumn{2}{|l|}{ Model 2} \\
\hline & Odds ratio & $95 \% \mathrm{Cl}$ & Odds ratio & $95 \% \mathrm{Cl}$ \\
\hline \multicolumn{5}{|l|}{ Child's gender } \\
\hline Female & Ref. & & Ref. & \\
\hline Male & 1.013 & $0.693-1.482$ & 0.998 & $0.684-1.456$ \\
\hline Child's age (continuous from 0 to 4 ) & 0.883 & $0.772-1.008$ & 0.889 & $0.780-1.013$ \\
\hline \multicolumn{5}{|l|}{ Relationship to household head } \\
\hline Biological child & Ref. & & Ref. & \\
\hline Grandchild & 1.660 & $0.814-3.386$ & 1.758 & $0.864-3.577$ \\
\hline Other & 1.462 & $0.614-3.481$ & 1.369 & $0.578-3.242$ \\
\hline \multicolumn{5}{|l|}{ Household head's gender } \\
\hline Female & Ref. & & Ref. & \\
\hline Male & 1.125 & $0.706-1.792$ & 1.118 & $0.708-1.764$ \\
\hline \multicolumn{5}{|l|}{ Age group (years) } \\
\hline$<30$ & Ref. & Ref. & Ref. & \\
\hline $30-34$ & 1.385 & $0.788-2.431$ & 1.374 & $0.796-2.372$ \\
\hline $35-39$ & 1.358 & $0.721-2.557$ & 1.325 & $0.711-2.467$ \\
\hline $40-49$ & 1.062 & $0.535-2.107$ & 1.005 & $0.510-1.984$ \\
\hline$\geq 50$ & 0.809 & $0.372-1.760$ & 0.752 & $0.346-1.633$ \\
\hline \multicolumn{5}{|l|}{ Education level } \\
\hline No education/Primary level & Ref. & & Ref. & \\
\hline Secondary level or higher & 0.972 & $0.636-1.485$ & 0.989 & $0.648-1.509$ \\
\hline \multicolumn{5}{|l|}{ Household wealth index } \\
\hline Poorer & Ref. & & Ref. & \\
\hline Poor & 1.506 & $0.838-2.704$ & 1.475 & $0.836-2.603$ \\
\hline Middle & $1.937^{*}$ & $1.018-3.686$ & $1.923^{*}$ & $1.018-3.631$ \\
\hline Rich & 1.663 & $0.912-3.032$ & 1.587 & $0.867-2.905$ \\
\hline Richer & 1.598 & $0.833-3.067$ & 1.594 & $0.760-3.344$ \\
\hline \multicolumn{5}{|l|}{ Number of household members } \\
\hline 5 or fewer than 5 & Ref. & & Ref. & \\
\hline More than 5 & 0.968 & $0.615-1.525$ & 1.011 & $0.642-1.591$ \\
\hline \multicolumn{5}{|l|}{ Number of children under five } \\
\hline One & Ref. & & Ref. & \\
\hline More than 1 & 1.212 & $0.790-1.859$ & 1.193 & $0.781-1.823$ \\
\hline \multicolumn{5}{|l|}{ Paying attention to the child } \\
\hline Less attention & Ref. & & Ref. & \\
\hline More attention & 0.809 & $0.557-1.177$ & 0.815 & $0.564-1.178$ \\
\hline \multicolumn{5}{|l|}{ Playing with the child in the past three days } \\
\hline No playing & Ref. & & Ref. & \\
\hline Playing at least once within the past 3 days & 1.228 & $0.727-2.076$ & 1.205 & $0.717-2.027$ \\
\hline \multicolumn{5}{|l|}{ Severity of diarrhea } \\
\hline Without blood & Ref. & & Ref. & \\
\hline With blood & $2.821^{* * *}$ & $1.499-5.311$ & $2.813^{* * *}$ & $1.508-5.251$ \\
\hline
\end{tabular}


Table 4 Multilevel logistic regressions predicting factors associated with appropriate treatment for childhood diarrhea in Nyanza Province, Kenya (Continued)

\begin{tabular}{|c|c|c|c|c|}
\hline \multicolumn{5}{|c|}{ Possession of at least one media device } \\
\hline No & Ref. & & Ref. & \\
\hline Yes & 0.641 & $0.338-1.216$ & 0.650 & $.347-1.217$ \\
\hline \multicolumn{5}{|l|}{ Community Variables } \\
\hline \multicolumn{5}{|l|}{ Area } \\
\hline Urban & & & Ref. & \\
\hline Rural & & & 1.117 & $0.551-2.265$ \\
\hline \multicolumn{5}{|l|}{ Performance of CHWs } \\
\hline None/Poor & & & Ref. & \\
\hline Middle & & & $1.655^{*}$ & $1.080-2.538$ \\
\hline High & & & $1.938^{* *}$ & $1.201-3.127$ \\
\hline Community Level Variance & $0.516(0.224)$ & & 0.402 & \\
\hline Log likelihood & -484.54 & & -479 & \\
\hline Likelihood-ratio test ( $p$ value) & 0.030 & & 0.027 & \\
\hline
\end{tabular}

${ }^{*} \leq 0.05 *{ }^{*} \leq 0.01{ }^{* * *} \leq 0.001$

be the reason why the diarrhea cases in urban areas, which would be the areas with higher population densities, were higher than rural.

The incidence of diarrhea among children under 1 and aged 1-2 years was $20.9 \%$ and $25 \%$ respectively, while the percentage among children aged 4-5 years was $8.5 \%$. Children under two years old in this study were the most vulnerable in terms of the diarrheal infection. Another study also shows that the young age of the child, especially after exclusive breastfeeding, is linked to a greater risk of having diarrhea [20, 21]. Appropriate infant feeding following exclusive breastfeeding is an important intervention for the reduction of childhood diarrhea and improvement of the child's health [22-25].

If children were left alone in the house or only with other siblings under 10 years of age, their parents would by implication pay less attention to those children than others. As a result, children without sufficient attention are more likely to have accidents or behave dangerously, such as eating dirty food from the floor [11]. Furthermore, parents who did not stay with their children may work outside of the house. Parental employment is reported as a significant factor in childhood diarrhea [26]; it is also reported that women's participation in income generating activities has positive effect on their children's nutritional condition [22]. Further research is needed to clarify details regarding children who are left alone and the effects of this.

In addition, the effectiveness of water treatment was reported by other researchers as an important factor in preventing childhood diarrhea [27-31]. Our study also suggested that water treatment practices are recommended interventions for the prevention of childhood diarrhea.

\section{Determinants of appropriate treatment for childhood diarrhea}

Although we included a range of variables in the analysis to examine significant factors for the appropriate treatment of childhood diarrhea, household wealth index, severity of diarrhea and the middle and high performance of CUs were the only significant variables in this study. A study in Kenya by Olson et al demonstrates how CHWs are important health personnel who could play a role in delivering health-related information [32]. Colvin [33] also reported that a middle layer between the community and a health facility, such as the CHWs, is an important element in influencing appropriate care-seeking behavior. In addition, other studies describe the effectiveness of CHWs in promoting the uptake of appropriate treatment for childhood diarrhea [34]. A wider implementation of CHWs, through CU establishments, would be the effective means of improving the accessibility of health care, regardless of individual factors. Although a study has been done that assesses the influencing factors of CHW' performance $[5,35]$, it is important to conduct further research on interventions to increase and sustain the high performance of CHWs and CUs.

One key reason for not seeking care is cost of treatment [36]. It is also reported that household wealth was a determinant of health seeking behavior for childhood diarrhea [37]. The trend that individuals from poorer households tend to be less likely to seek health services is also reported in studies of other curative [38] and preventive services, such as immunization [39]. In these 
studies, we see that the caregivers in wealthier households could afford to pay not only the cost of health services but also transportation and other costs.

As this study identified, severity of diarrhea is an important factor associated with appropriate treatment. Lack of maternal perception on the seriousness of the illness was shown to be the primary reason for no treatment [36]. In addition, perception of severity of illness is associated with appropriate health seeking behavior, such as health facility visitation [40]. Bloody diarrhea would make caregivers think seriously about their child's diarrhea and encourage them to take necessary actions.

\section{Limitations}

This present study has reported the significant factors, including the performance of CUs, associated with diarrhea prevalence and appropriate treatment for diarrhea among children under five in western Kenya.

However, this study is a cross-sectional study. Since the effects of CUs could change over time, and there is a possibility that areas with a high prevalence of diarrhea were selected when establishing the CUs, further longitudinal research is necessary to clarify the causal connection between $\mathrm{CHW}$ performance, diarrhea prevalence and appropriate treatment. The evaluation framework of the CUs' performance is another limitation. Although we utilized the official evaluation framework developed by the Kenyan $\mathrm{MoH}$, the CU performance markers used in this study related to group level performance, which is not equivalent to individual performance. Therefore, our study shows only the association between group performance, prevalence of childhood diarrhea and appropriate treatment. Further research on the effects of CHWs needs to be conducted by using an evaluation framework that includes both personal and group performance indicators, such as number of households visited per month, job satisfaction and health knowledge, as well as evaluations from supervisors and community members. Since two of the three performance indicators derived from documentation, there is also a possibility that although the meetings were actually held, CUs did not submit minutes of meetings and were regarded as poorly performing. It would be better for further research to integrate indicators such as number of households visited into the performance evaluation framework. In addition, the causal relations among CU performance, household practices to prevent childhood diarrhea and uptake of appropriate treatment were unclear.

Since the MICS data was collected using a structured questionnaire and not direct observation, several variables, such as the severity of diarrhea, means of water treatment and drinking water resource, may not be accurate. Although this study assumed that household heads would be the most influential people in decision making, there is a possibility that mothers or other family members have autonomy to make decisions about care-seeking for children in their households.

Furthermore, periods of time for two variables, child left alone more than once and playing with the child, were not measured in this study. It would be better to assess the period of each activity and make their effects clearer.

\section{Conclusion}

Our study has clarified several factors significantly associated with diarrhea prevalence and appropriate treatment for diarrhea for children under five in Nyanza Province, Kenya. In this study, we addressed a significant factor for both outcomes: the performance of CUs, represented by the performance of CHWs, CHC and CHEWs. Although their performance was significantly associated with the higher prevalence of childhood diarrhea, the areas with a high prevalence of diarrhea would have been primarily selected to establish CUs. However, higher CU performance was also significantly associated with taking an appropriate treatment for childhood diarrhea. It is suggested that high performance of $\mathrm{CU}$ might have a positive effect on encouraging community members to select appropriate treatment for childhood diarrhea. With full consideration of the evaluation framework, further studies are needed in order to describe the causal connection between $\mathrm{CHW}$ performance and diarrhea prevention and treatment, as well as for better understanding of long-term impacts.

\section{Abbreviations \\ CHC: Community health committee; CHEW: Community health extension worker; CHIS: Community health information system; CHS: Community health strategy; CHWs: Community health workers; CU: Community unit; EAs: Enumeration areas; KDHS: Kenya demographic health survey; KNBS: Kenya National Bureau of Statistics; MICS: Multiple indicator cluster survey; $\mathrm{MoH}$ : Ministry of health; MoPHS: Ministry of public health and sanitation; NHPP II: National health sector strategic plan 2005-2010; PPS: Probability proportional to size}

\section{Acknowledgements}

We would like to thank the interviewers and supervisors for their good work in both the MICS survey and the government survey. Special thanks to John Ndegwa Wagai in UNICEF, Kenya for the support. We are also grateful to the children and families for their participation in this study.

\section{Funding}

No funding.

\section{Availability of data and materials}

Although we directly requested UNICEF Kenya to provide the MICS dataset, the dataset supporting the conclusions of this article is also available in the MICS survey home page, http://mics.unicef.org/surveys.

\section{Authors' contributions}

YK was responsible for designing the study and drafting the manuscript. $\mathrm{JT}$ and $\mathrm{KO}$ contributed by performing statistical analysis and writing the manuscript. $\mathrm{KO}$ was the responsible persons at $\mathrm{MoH}$, Kenya and made a contribution to areas under discussion. SH advised on statistical analysis and gave approval to submit. All authors read and approved the final manuscript.

Competing interests

The authors declare that they have no competing interests. 


\section{Consent for publication}

Not applicable.

\section{Ethics approval and consent to participate}

The study is based on secondary data analysis of publicly available survey data with all identifying information removed. Informed consent was obtained from all participants in the survey before asking any questions. The approvals for data utilization were given from UNICEF. In addition, a list of community units was provided by the Ministry of Health, Kenya. The Ethical Committee of Nagasaki University, Japan provided ethical approval for this research.

\section{Author details}

'Graduate School of Biomedical Sciences, Nagasaki University, 1-7-1 Sakamoto, Nagasaki, Japan. ${ }^{2}$ Strengthening Pro-Poor Community Health Project, Lagos, Nigeria. ${ }^{3}$ Ministry of Health, Nairobi, Kenya.

Received: 22 August 2015 Accepted: 3 February 2017

Published online: 16 February 2017

\section{References}

1. Chen L, Evans T, Anand S, Ivey Boufford J, Brown H, Chowdhury M, Cueto M, Dare L, Dussault G, Elzinga G, et al. Human resources for health: Overcoming the crisis. Lancet. 2004;364(9449):1984-90.

2. Haines A, Sanders D, Lehmann U, Rowe AK, Lawn JE, Jan S, Walker DG, Bhutta Z. Achieving child survival goals: potential contribution of community health workers. Lancet. 2007;369(9579):2121-31.

3. Tulenko K, Mogedal S, Afzal MM, Frymus D, Oshin A, Pate M, Quain E, Pine A, Wynd S, Zodpey S. Community health workers for universal health-care coverage: from fragmentation to synergy. Bull World Health Organ. 2013; 91(11):847-52.

4. Kenya MoH. Reversing the Trends: The Second National Health Sector Strategic Plan of Kenya- NHSSP II (2005-2010). Nairobi: Ministry of Health; 2005. http://www.ihpmr.org/wp-content/uploads/2012/10/NHSSP-II_20052010.pdf.

5. Kawakatsu Y, Sugishita T, Jackson K, Ishimura A, Honda S. Factors influencing the performance of community health workers in Kisumu West, Kenya. Primary Health Care Res Dev. 2012;1-7.

6. Kawakatsu Y, Honda S. Individual-, family- and community-level determinants of full vaccination coverage among children aged 12-23 months in western Kenya. Vaccine. 2012;30(52):7588-93.

7. Black RE, Cousens $\mathrm{S}$, Johnson HL, Lawn JE, Rudan I, Bassani DG, Jha P, Campbell H, Walker CF, Cibulskis R, et al. Global, regional, and nationa causes of child mortality in 2008: a systematic analysis. Lancet. 2010; 375(9730):1969-87.

8. Jones G, Steketee RW, Black RE, Bhutta ZA, Morris SS. How many child deaths can we prevent this year? Lancet. 2003;362(9377):65-71.

9. Macro KNBoSKal. 2008-09 Kenya Demographic and Health Survey. Calverton, Maryland: KNBS and ICF Macro; 2010.

10. Olayo R, Wafula C, Aseyo E, Loum C, Kaseje D. A quasi-experimental assessment of the effectiveness of the Community Health Strategy on health outcomes in Kenya. BMC Health Serv Res. 2014;14 Suppl 1:S3.

11. National Bureau of statistics K. Nyanza Province Multiple Indicator Cluster Survey 2011, Final Report. Nairobi, Kenya: Kenya National Bureau of Statistics; 2013.

12. WHO/UNICEF. Core Questions on Drinking Water and Sanitation for Household Surveys. Geneva: World Health Organization; 2006.

13. Kenya National Bureau of statistics K. The 2009 Kenya Population and Housing Census. Nairobi: Kenya National Bureau of statistics, Kenya; 2010.

14. Chowdhury A, Chowdhury S, Islam M, Islam A, Vaughan J. Control of tuberculosis by community health workers in Bangladesh. Lancet. 1997;350:169.

15. Luby S, Agboatwalla M, Feikin D, Painter J, Billhimer W. Effect of handwashing on child health: a randomised controlled trial. Lancet. 2005; 366:225.

16. Luby S, Agboatwalla M, Painter J, Altaf A, Billhimer W, Hoekstra R. Effect of intensive handwashing promotion on childhood diarrhea in high-risk communities in Pakistan: a randomized controlled trial. JAMA. 2004; 291:2547.

17. Feikin DR, Audi A, Olack B, Bigogo GM, Polyak C, Burke H, Williamson J, Breiman RF. Evaluation of the optimal recall period for disease symptoms in home-based morbidity surveillance in rural and urban Kenya. Int J Epidemiol. 2010;39(2):450-8.
18. Luque Fernandez MA, Mason PR, Gray H, Bauernfeind A, Fesselet JF, Maes P. Descriptive spatial analysis of the cholera epidemic 2008-2009 in Harare, Zimbabwe: a secondary data analysis. Trans R Soc Trop Med Hyg. 2011; 105(1):38-45.

19. Ferrari MJ, Djibo A, Grais RF, Bharti N, Grenfell BT, Bjornstad ON. Rural-urban gradient in seasonal forcing of measles transmission in Niger. Proc R Soc B Biol Sci. 2010;277(1695):2775-82.

20. Page A, Hustache S, Luquero F, Djibo A, Manzo M, Grais R. Health care seeking behavior for diarrhoea in children under 5 in rural Niger: results of a cross-sectional survey. BMC Public Health. 2011;11:389.

21. Irshad M, Hayat M, Ahmad A, Khalil B, Hussain M. Case fatality rate and etiological factors of malnutrition in children less than 5 years of age. J Postgrad Med Inst. 2014;28(1):42-8.

22. Brhane $G$, Regassa N. Nutritional status of children under five years of age in Shire Indaselassie, North Ethiopia: Examining the prevalence and risk factors. Kontakt. 2014;16(3):e161-70.

23. Etiler N, Velipasaoglu S, Aktekin M. Risk factors for overall and persistent diarrhoea in infancy in Antalya, Turkey: a cohort study. Public Health. 2004; 118(1):62-9.

24. Arifeen S, Black RE, Antelman G, Baqui A, Caulfield L, Becker S. Exclusive breastfeeding reduces acute respiratory infection and diarrhea deaths among infants in Dhaka slums. Pediatrics. 2001;108(4):E67.

25. Oddy WH, Kendall GE, Blair E, De Klerk NH, Stanley FJ, Landau LI, Silburn S, Zubrick S. Breast feeding and cognitive development in childhood: A prospective birth cohort study. Paediatr Perinat Epidemiol. 2003;17(1):81-90.

26. Hussain TM, Smith JF. The relationship between maternal work and other socioeconomic factors and child health in Bangladesh. Public Health. 1999; 113(6):299-302.

27. Luby SP, Agboatwalla M, Painter J, Altaf A, Billhimer W, Keswick B, Hoekstra RM. Combining drinking water treatment and hand washing for diarrhoea prevention, a cluster randomised controlled trial. Trop Med Int Health. 2006; 11(4):479-89.

28. Organization WH. Water quality interventions to prevent diarrhoea: Cost and cost-effectiveness. Geneva: WHO press; 2008. http://www.who.int/ water_sanitation_health/economic/prevent_diarrhoea.pdf.

29. Reller ME, Mendoza CE, Lopez MB, Alvarez M, Hoekstra RM, Olson CA, Baier KG, Keswick BH, Luby SP. A randomized controlled trial of household-based flocculant-disinfectant drinking water treatment for diarrhea prevention in rural Guatemala. Am J Trop Med Hyg. 2003;69(4):411-9.

30. Clasen T, Parra GG, Boisson S, Collin S. Household-based ceramic water filters for the prevention of diarrhea: A randomized, controlled trial of a pilot program in Colombia. Am J Trop Med Hyg. 2005;73(4):790-5.

31. Clasen TF, Alexander KT, Sinclair D, Boisson S, Peletz R, Chang HH, Majorin F, Cairncross $\mathrm{S}$. Interventions to improve water quality for preventing diarrhoea. Cochrane Database Syst Rev. 2015;10.

32. Olson CK, Blum LS, Patel KN, Oria PA, Feikin DR, Laserson KF, Wamae AW, Bartlett AV, Breiman RF, Ram PK. Community case management of childhood diarrhea in a setting with declining use of oral rehydration therapy: findings from cross-sectional studies among primary household caregivers, Kenya, 2007. Am J Trop Med Hyg. 2011;85(6):1134-40.

33. Colvin CJ, Smith HJ, Swartz A, Ahs JW, de Heer J, Opiyo N, Kim JC, Marraccini T, George A. Understanding careseeking for child illness in subSaharan Africa: a systematic review and conceptual framework based on qualitative research of household recognition and response to child diarrhoea, pneumonia and malaria. Soc Sci Med. 2013;86:66-78.

34. Perry HB, Zulliger R, Rogers MM. Community Health Workers in Low-, Middle-, and High-Income Countries: An Overview of Their History, Recent Evolution, and Current Effectiveness. Annu Rev Public Health. 2014;35(1):399-421.

35. Kawakatsu Y, Sugishita T, Tsutsui J, Oruenjo K, Wakhule S, Kibosia K, Were E, Honda S. Individual and contextual factors associated with community health workers' performance in Nyanza Province, Kenya: a multilevel analysis. BMC Health Serv Res. 2015;15:442.

36. Das SK, Nasrin D, Ahmed S, Wu Y, Ferdous F, Farzana FD, Khan SH, Malek MA, Arifeen SE, Levine MM, et al. Health care-seeking behavior for childhood diarrhea in mirzapur, Rural Bangladesh. Am J Trop Med Hyg. 2013:89 Suppl 1:62-8.

37. Malhotra N, Upadhyay RP. Why are there delays in seeking treatment for childhood diarrhoea in India? Acta Paediatr Int J Paediatrics. 2013;102(9):e413-8.

38. Mebratie AD, Van De Poel E, Yilma Z, Abebaw D, Alemu G, Bedi AS. Healthcare-seeking behaviour in rural Ethiopia: Evidence from clinical vignettes. BMJ Open. 2014;4(2):e004020. 
39. Clouston S, Kidman R, Palermo T. Social inequalities in vaccination uptake among children aged 0-59 months living in Madagascar: An analysis of Demographic and Health Survey data from 2008 to 2009. Vaccine. 2014; 32(28):3533-9.

40. Yoder PS, Hornik RC. Symptoms and perceived severity of illness as predictive of treatment for diarrhea in six Asian and African sites. Soc Sci Med. 1996;43(4):429-39.

Submit your next manuscript to BioMed Central and we will help you at every step:

- We accept pre-submission inquiries

- Our selector tool helps you to find the most relevant journal

- We provide round the clock customer support

- Convenient online submission

- Thorough peer review

- Inclusion in PubMed and all major indexing services

- Maximum visibility for your research

Submit your manuscript at www.biomedcentral.com/submit 